\title{
Robot-assisted revision of sacroiliac joint fusion using a triangular titanium implant in an S2-alar-iliac trajectory: illustrative case
}

\author{
Matthew Triano, MS, ${ }^{1}$ Islam Fayed, MD, MS, ${ }^{2}$ and Faheem A. Sandhu, MD, $\mathrm{PhD}^{2}$ \\ ${ }^{1}$ Georgetown University School of Medicine, Washington, DC; and ${ }^{2}$ Department of Neurosurgery, MedStar Georgetown University Hospital, Washington, DC
}

BACKGROUND Sacroiliac joint (SIJ) dysfunction can lead to significant pain and disability, greatly impairing quality of life. Arthrodesis may take up to 1 year to occur, after which revision can be considered. There is a need for highly accurate and reproducible techniques for revision that allow for purchase through undisturbed bone to prevent prolonged pain and disability. Moreover, a minimally invasive technique for revision would be favorable for recovery, particularly in elderly patients.

OBSERVATIONS An 84-year-old man with a prior history of lumbar fusion presented with severe buttock pain limiting ambulation and sitting because of the failure of arthrodesis after SIJ fusion 1 year earlier. He underwent revision using a triangular titanium implant (TTI) in an S2-alar-iliac (S2-Al) trajectory under robotic guidance, which is a novel technique not yet described in the literature. The patient's pain largely resolved, he was able to ambulate independently, and his quality of life improved tremendously. There were no complications of surgery.

LESSONS Placement of a TTI using an S2-Al trajectory is a safe and effective method for revision that can be considered for elderly patients. Robotassisted navigation can be used to facilitate an accurate and reproducible approach using a minimally invasive approach.

https://thejns.org/doi/abs/10.3171/CASE2169

KEYWORDS arthrodesis; case reports; reoperation; robotic surgical procedures; sacroiliac joint

Sacroiliac joint (SIJ) dysfunction can lead to significant pain and disability, greatly impairing quality of life. SIJ dysfunction is involved in up to $30 \%$ of patients with low back pain. ${ }^{1,2}$ Up to $40 \%$ of patients with SIJ disease have undergone previous lumbar arthrodesis. ${ }^{3}$ Several studies have shown significant improvement in pain, disability, and quality of life after SIJ fusion (SIJF). ${ }^{1-7}$ Although surgical intervention can significantly improve patient symptoms, arthrodesis may take more than 1 year to occur. ${ }^{3}$

Robot-assisted spinal surgery has recently grown in popularity and has been used for S2-alar-iliac (S2-Al) screw placement in deformity cases. ${ }^{8,9}$ Planning screw trajectories using software can increase the reliability of percutaneous techniques for cases in which there is suboptimal visualization of surgical targets, ${ }^{9}$ making it useful for minimally invasive surgery. Here, we detail the first published use of robotic assistance for placement of triangular titanium implants (TTIs) for revision of SIJF using an S2-Al trajectory.

\section{Illustrative Case}

An 84-year-old man with a history of an L4-S1 laminectomy and fusion performed elsewhere presented with severe left buttock pain on ambulation. The pain had developed 6 years earlier after a motor vehicle collision. He reported temporary relief from SIJ steroid injections. Physical examination was notable for tenderness to palpation over the left buttock and a positive FABER (flexion, abduction, and external rotation) sign.

The patient had undergone minimally invasive left SIJF elsewhere with implantation of two TTls (Fig. 1). However, his pain worsened and remained constant while at rest postoperatively. At 11 months postoperatively, imaging revealed the failure of arthrodesis with lack of bony growth over the implants (Fig. 2). At 12 months postoperatively, he underwent revision, with removal of hardware and implantation of a $\mathrm{TTI}$ in an S2-Al trajectory using robotic assistance.

ABBREVIATIONS AP = anteroposterior; $\mathrm{CT}=$ computed tomography; K-wire = Kirschner wire; S2-AI = S2-alar-iliac; SIJ = sacroiliac joint; SIJF = SIJ fusion; $\mathrm{TTI}=$ triangular titanium implant.

INCLUDE WHEN CITING Published July 5, 2021; 10.3171/CASE2169.

SUBMITTED February 3, 2021. ACCEPTED April 30, 2021.

(C) 2021 The authors, CC BY-NC-ND 4.0 (http://creativecommons.org/licenses/by-nc-nd/4.0/). 


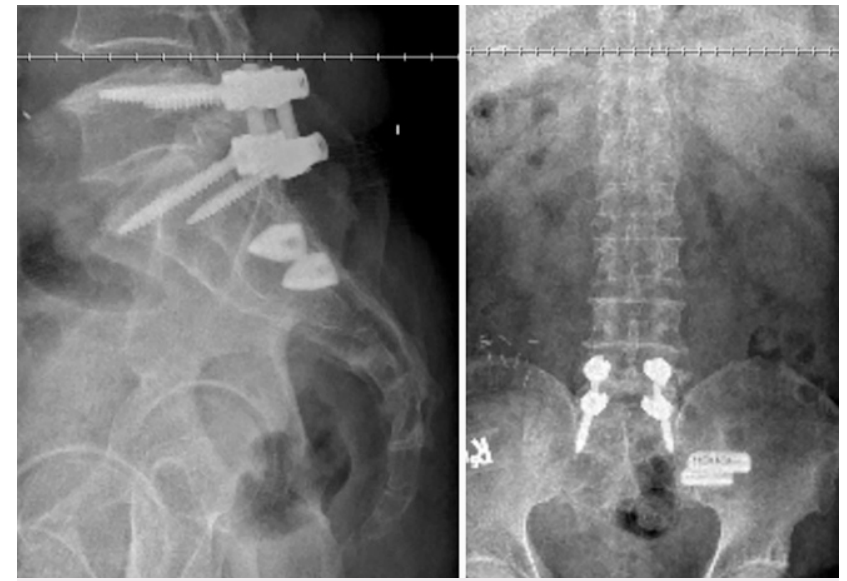

FIG. 1. Lateral (left) and AP (right) preoperative radiographs demonstrating prior L5-S1 fusion and two TTIs across the left SIJ.

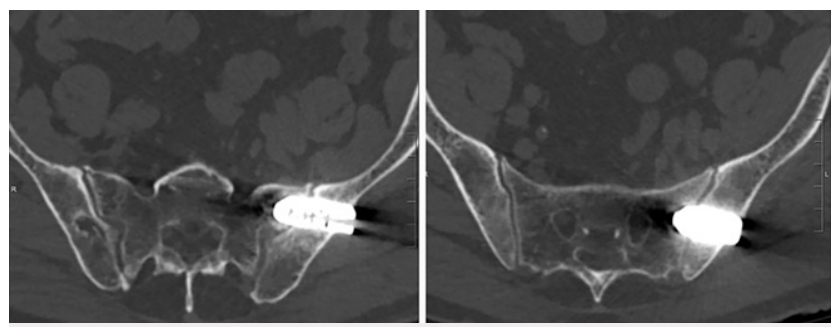

FIG. 2. Axial CT demonstrating prior superior (left) and inferior (right) TTIs across the left SIJ with pseudarthrosis.

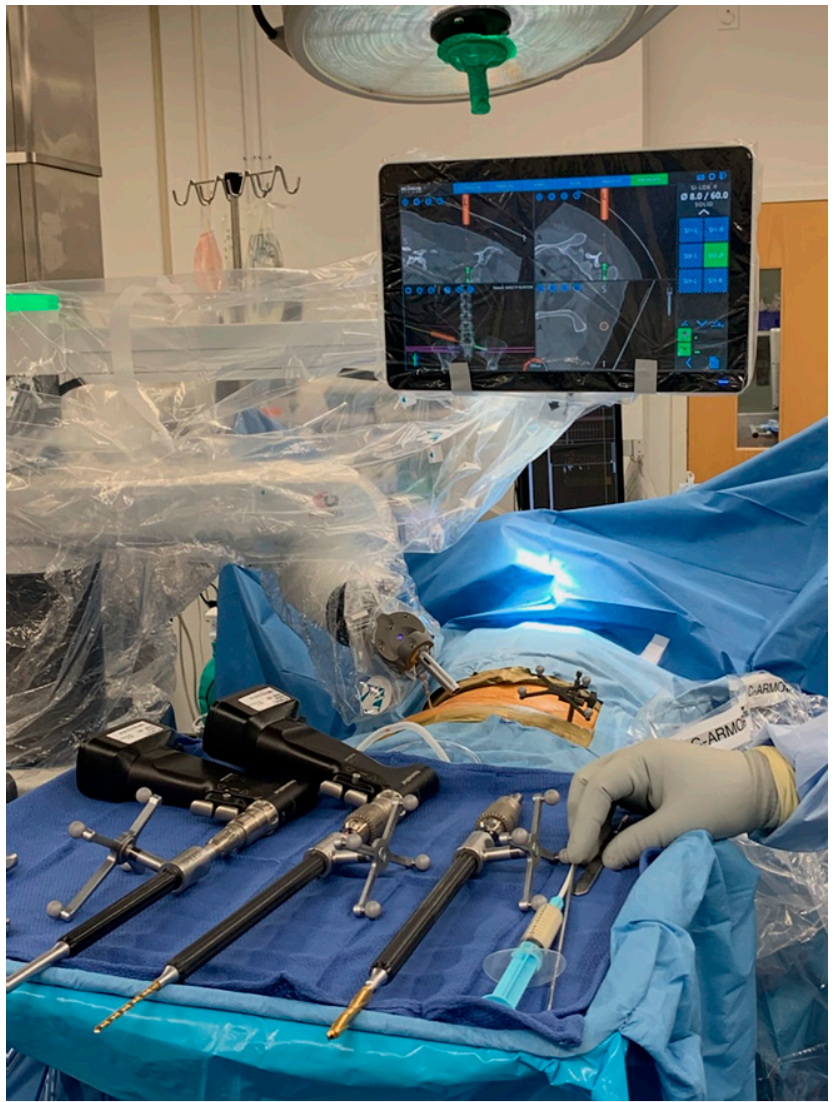

FIG. 3. Operating room setup demonstrating patient in the prone position, robotic arm on the patient's left, planned trajectories on the attached monitor, and Mayo stand with navigation-assisted instruments.

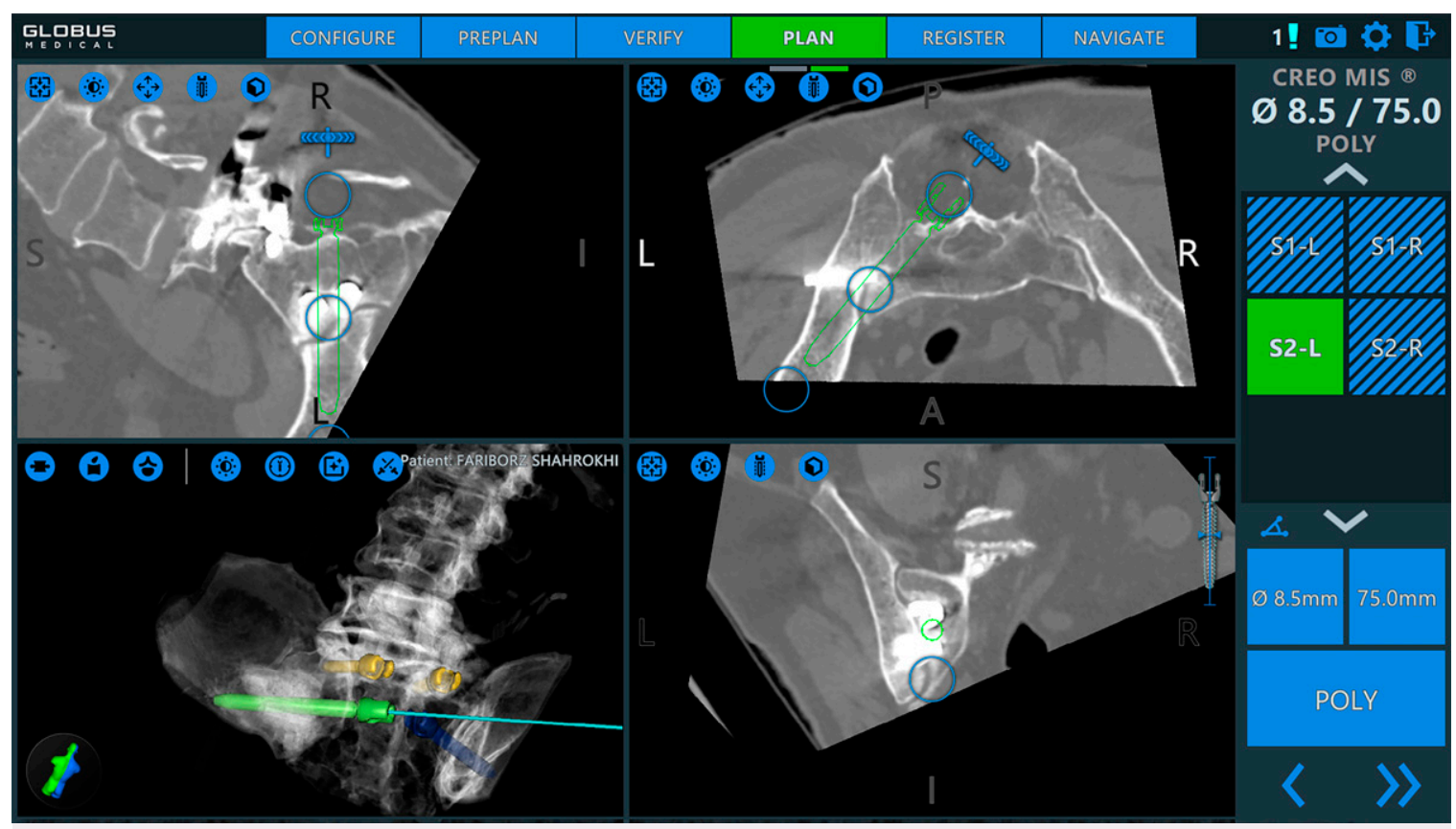

FIG. 4. Software interface demonstrating planned S2-Al trajectory using preoperative CT. 


\section{Operative Procedure}

After induction of anesthesia, the patient was placed prone on an open Jackson table. The previous left lateral hip incision was opened, and blunt finger dissection was used to find the previous left sacroiliac fixation implants. Serial dilators were then docked over the first implant. A guidewire was passed through the posterior cannula of the TTI (iFuse Implant System, SI-BONE, Inc.) to allow a threaded post to be secured. Osteotomes and a slap hammer were used to release the implants. Considerable time and effort were required to remove the implants, possibly because of excessive bony apposition or worn threading within the devices.

Next, the robotic system (ExcelsiusGPS, Globus Medical) was positioned on the patient's left side (Fig. 3). Trajectories were mapped beforehand using preoperative computed tomography (CT) and the system's accompanying software (Fig. 4). A stab incision was made over the right and left superior iliac crests for attachment of the dynamic reference array and surveillance pin. Image registration was performed by merging a preoperative CT scan with anteroposterior (AP) and lateral fluoroscopic images. The planned trajectory was identical to that of an S2-Al screw.

The robotic arm was brought into position and a midline skin incision was made. A high-speed burr was used to perforate the bone, followed by use of a navigated drill to reach a depth of approximately 70 $\mathrm{mm}$. The path was widened to $7.5 \mathrm{~mm}$ using serial taps. A Kirschner (K)-wire was placed into the pilot hole, and a broach was passed over it to a depth of $75 \mathrm{~mm}$. The TTI was then passed over the K-wire and advanced through the sacrum, past the SIJ, and into the ilium, which was confirmed by fluoroscopy (Fig. 5A).

\section{Postoperative Course}

Immediately postoperatively, the patient reported that his preoperative buttock pain had significantly improved. Radiographs showed stable instrumentation across the SIJ (Fig. 5B). At 3 weeks postoperatively, he was ambulating independently at home using a walker. By 12 weeks, he reported mild buttock discomfort on ambulation. He continues to ambulate independently and reports an improved quality of life. No postoperative complications were observed.

\section{Discussion}

\section{Observations}

SIJ dysfunction is a common cause of lower back pain, especially among patients with prior lumbar fusion. ${ }^{1-3}$ The economic burden of treatment is significant, with an average cost per patient of $\$ 63,913$. $^{10}$ SIJF has been demonstrated to significantly improve pain, disability, and quality of life in several retrospective studies ${ }^{1-3,7}$ and three randomized controlled trials. ${ }^{4-6}$

Revision rates for SIJF are acceptably low, ranging from $0 \%$ to $17 \%$ with a mean of $6 \%$ in a review by Cleveland et al. ${ }^{1}$ Two meta-analyses cited rates of $2.1 \%$ and $2.6 \%$ across 432 and 720 patients, respectively. ${ }^{7,11}$ Because arthrodesis may take more than 1 year to occur, ${ }^{3}$ less obvious malpositioning that is not immediately addressed may prolong pain and disability for more than 12 months. Robot-assisted platforms for SIJF may prevent inaccuracy given their reproducibility of trajectory and advantage over conventional fluoroscopy for anatomically challenging areas, such as the pelvis. ${ }^{9} \mathrm{CT}$ navigation may also enhance accuracy by facilitating three-dimensional visualization of pelvic anatomy. ${ }^{12-14}$ However, calibration of CT navigation may be suboptimal in minimally invasive procedures because of a lack of exposed internal structures, in which case robotic platforms may be more useful.

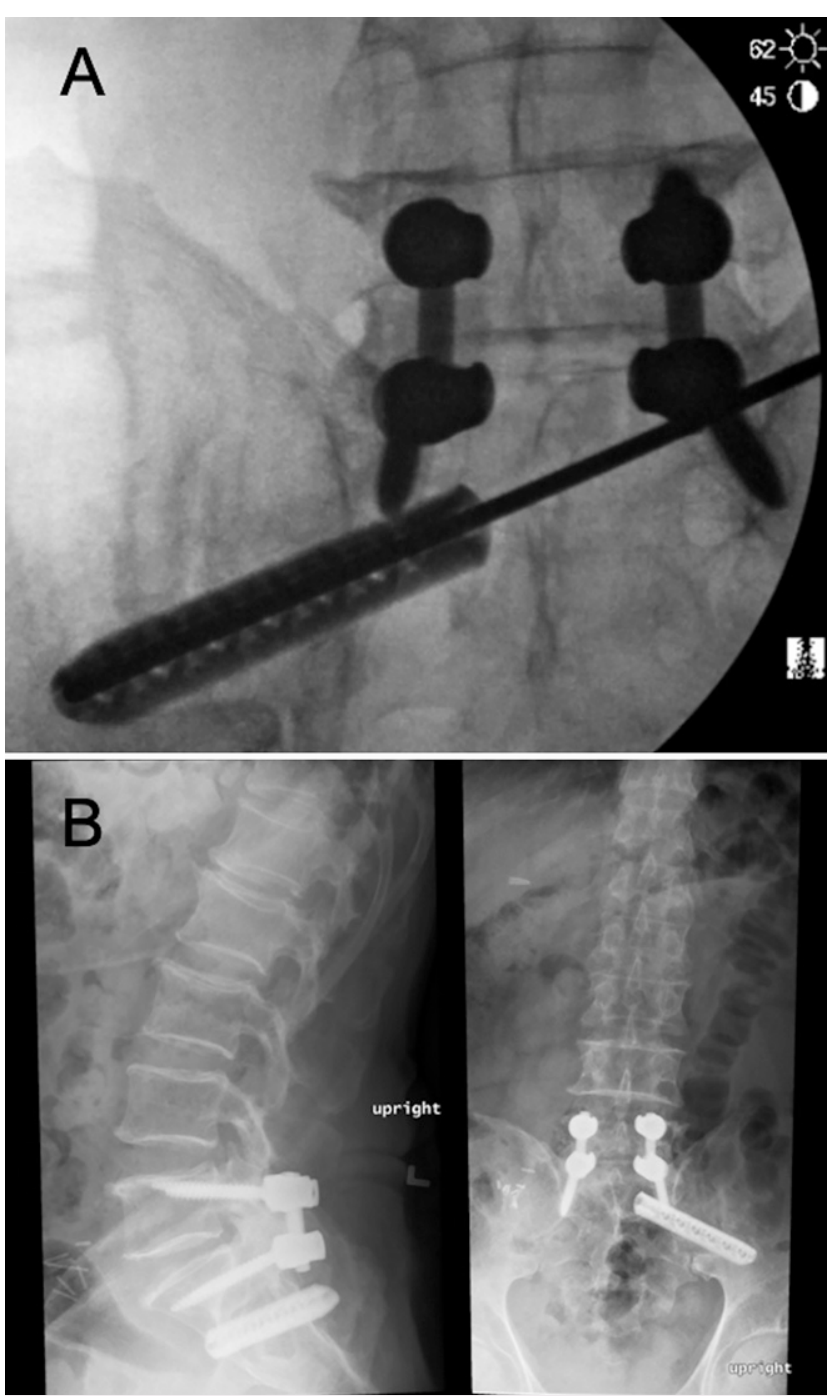

FIG. 5. A: AP radiograph showing intraoperative introduction of TTI over K-wire placed using robotic guidance. B: Lateral (left) and AP (right) postoperative radiographs demonstrating successful placement of TTI in an S2-Al trajectory across the left SIJ.

SIJ implants are typically placed from lateral to medial, and revisions may require an alternative trajectory to allow for purchase through undisturbed bone. ${ }^{15}$ This revision can be achieved using S2-Al screws, which can be placed using robotic guidance., ${ }^{8,916}$ However, screws have a propensity to loosen and lack the osteogenic properties that TTls possess. One study that examined 4-year revision rates for SIJ arthrodesis indicated a $30.8 \%$ rate for screws but only a $5.7 \%$ rate once TTls were introduced into practice. ${ }^{17}$

\section{Lessons}

In this report, our patient underwent revision of SIJF for pseudarthrosis and pain persisting 1 year after surgery. Removal of instrumentation and introduction of a TTI across the joint in an S2-Al trajectory led to a resolution of symptoms. Robotic assistance was helpful for K-wire placement given the system's reliability of trajectory and the complex anatomy of the pelvic region. It also allowed for a minimally invasive approach to maximize recovery in an elderly patient. ${ }^{18}$ Because this 
technique has not been described previously, independent validation is required. Implementation of robotic navigation for SIJF may help further improve accuracy and prevent pseudarthrosis, prolonged pain, disability, and increased costs.

Placement of a TTI using an S2-Al trajectory is a safe and effective method for revision of SIJF. Robot-assisted navigation can be used to facilitate an accurate and reproducible approach using minimally invasive techniques.

\section{References}

1. Cleveland AW III, Nhan DT, Akiyama M, et al. Mini-open sacroiliac joint fusion with direct bone grafting and minimally invasive fixation using intraoperative navigation. J Spine Surg. 2019;5(1):31-37.

2. Darr E, Meyer SC, Whang PG, et al. Long-term prospective outcomes after minimally invasive trans-iliac sacroiliac joint fusion using triangular titanium implants. Med Devices (Auckl). 2018;11:113-121.

3. Duhon BS, Bitan F, Lockstadt $\mathrm{H}$, et al. Triangular titanium implants for minimally invasive sacroiliac joint fusion: 2-year follow-up from a prospective multicenter trial. Int J Spine Surg. 2016;10:13.

4. Dengler JD, Kools D, Pflugmacher R, et al. 1-year results of a randomized controlled trial of conservative management vs. minimally invasive surgical treatment for sacroiliac joint pain. Pain Physician. 2017;20(6):537-550.

5. Polly DW, Swofford J, Whang PG, et al. Two-year outcomes from a randomized controlled trial of minimally invasive sacroiliac joint fusion vs. non-surgical management for sacroiliac joint dysfunction. Int J Spine Surg. 2016;10:28.

6. Whang P, Cher D, Polly D, et al. Sacroiliac joint fusion using triangular titanium implants vs. non-surgical management: six-month outcomes from a prospective randomized controlled trial. Int J Spine Surg. 2015:9:6.

7. Shamrock AG, Patel A, Alam M, et al. The safety profile of percutaneous minimally invasive sacroiliac joint fusion. Global Spine J. 2019;9(8):874-880.

8. Laratta JL, Shillingford JN, Lombardi JM, et al. Accuracy of S2 alariliac screw placement under robotic guidance. Spine Deform. 2018; 6(2):130-136.

9. Bederman SS, Hahn P, Colin V, et al. Robotic guidance for S2-alar-iliac screws in spinal deformity correction. Clin Spine Surg. 2017;30(1):E49-E53.

10. Ackerman SJ, Polly DW Jr, Knight T, et al. Nonoperative care to manage sacroiliac joint disruption and degenerative sacroiliitis: high costs and medical resource utilization in the United States Medicare population. J Neurosurg Spine. 2014;20(4):354-363.

11. Heiney J, Capobianco R, Cher D. A systematic review of minimally invasive sacroiliac joint fusion utilizing a lateral transarticular technique. Int J Spine Surg. 2015;9:40.

12. Lee DJ, Kim SB, Rosenthal P, et al. Stereotactic guidance for navigated percutaneous sacroiliac joint fusion. J Biomed Res. 2016; 30(2):162-167.

13. Ray WZ, Ravindra VM, Schmidt MH, Dailey AT. Stereotactic navigation with the 0 -arm for placement of S-2 alar iliac screws in pelvic lumbar fixation. J Neurosurg Spine. 2013;18(5):490-495.

14. Phan K, Li J, Giang G, et al. A novel technique for placement of sacro-alar-iliac (S2Al) screws by K-wire insertion using intraoperative navigation. J Clin Neurosci. 2017;45:324-327.

15. Menmuir B, Fielding L. Revision of minimally invasive sacroiliac joint fixation: technical considerations and case studies using decortication and threaded implant fixation revision procedure. Int $J$ Spine Surg. 2017;11(1):50-58.

16. Hu X, Lieberman IH. Robotic-guided sacro-pelvic fixation using S2 alar-iliac screws: feasibility and accuracy. Eur Spine J. 2017;26(3): 720-725.

17. Spain $\mathrm{K}$, Holt T. Surgical revision after sacroiliac joint fixation or fusion. Int J Spine Surg. 2017;11(1):5.

18. Ledonio CGT, Polly DW Jr, Swiontkowski MF, Cummings JT Jr. Comparative effectiveness of open versus minimally invasive sacroiliac joint fusion. Med Devices (Auckl). 2014;7(1):187-193.

\section{Disclosures}

The authors report no conflict of interest concerning the materials or methods used in this study or the findings specified in this paper.

\section{Author Contributions}

Conception and design: Sandhu. Acquisition of data: Triano, Fayed. Analysis and interpretation of data: all authors. Drafting the article: Triano. Critically revising the article: all authors. Reviewed submitted version of manuscript: Sandhu, Fayed. Approved the final version of the manuscript on behalf of all authors: Sandhu. Administrative/ technical/material support: Sandhu. Study supervision: Sandhu.

\section{Correspondence}

Faheem A. Sandhu: MedStar Georgetown University Hospital, Washington, DC. fasandhu@aol.com. 